\title{
O DIFERENCIAL DA CRÍTICA MATERIALISTA
}

\author{
Maria Elisa Cevasco*
}

Resumo: Este artigo discute a tradição da crítica cultural materialista, enfocando alguns dos principais nomes dessa tradição e aferindo a especificidade de sua contribuição.

Palavras-chave: Crítica cultural materialista, marxismo ocidental.

Abstract: This article presents the tradition of materialist cultural criticism through a discussion of some of its main practitioners. It also tries to evaluate their specific contribution.

Keywords: Materialist cultural criticism, Western Marxism.

\footnotetext{
* Professora Titular da Universidade de São Paulo (USP). Email: maece@ usp.br.

${ }^{1}$ Este artigo retoma várias ideias que foram apresentadas em outros artigos, em especial "Formas Trabalhando Formas", no prelo, e "Crítica Cultural Marxista”. Cadernos de Estudos Culturais, v. 2, 2010.
} 
$\mid 16$ |

O diferencial da crítica materialista

Qual a contribuição que a tradição materialista traz à crítica cultural? No sentido mais abrangente, pode-se dizer que a marca que distingue essa tradição variada é que, para ela, a cultura concretiza relações sócio-históricas e o trabalho da crítica é examinar os modos como a arte descreve e interpreta essas relações. Isso de saída confere ao trabalho crítico uma relevância social ampla, na medida mesmo em que examina a produção cultural como a formalização dos significados e valores de uma determinada sociedade. Para essa tradição, para falar como um de seus expoentes no Brasil, Roberto Schwarz, "se não for preciso adivinhar, pesquisar, construir, recusar aparências, consubstanciar intuições difíceis, a crítica não é crítica. Seu resultado não é a simples reiteração da experiência cotidiana, a cuja prepotência se opõe, cujas contradições explicita, cujas tendências acentua, com decisivo resultado de clarificação." (SCHWARZ, 2004, p. 105).

Pelo menos durante o século $X X$, era da sua maior visibilidade acadêmica, não foi este o sentido do trabalho da crítica hegemônica. É certo que esse século conheceu, também por conta da expansão inédita dos meios de comunicação e de reprodução e da própria pesquisa universitária, uma enorme variedade de métodos e modas teóricas. Muitas delas até concordariam que o social funciona como pano de fundo, mas a grande maioria rejeita as ligações formativas entre produção cultural e contexto sócio-histórico.

Essa rejeição tem um duplo efeito: por um lado funciona como uma forma de elevar a esfera da cultura, colocando a produção de significados e valores acima dos conflitos e interesses que regem a vida concreta. Nesse processo de abstração, tudo se passa como se fosse possível criticar a sociedade sem se imiscuir nela. Esse apartamento é fundamental para que essa prática se equilibre em uma postura a um só tempo crítica e conivente: considera a sociedade do ponto de vista de uma certa noção de humanismo liberal, como uma realização do espírito ou como um repositório de valores elevados. Uma vez que se propõe sempre neutra e apolítica, essa crítica acaba afirmando o modo de vida que 
pretende julgar. Tal procedimento neutraliza o enorme potencial cognitivo da análise da cultura.

Estas concepções distintas das relações cultura/sociedade polarizou o debate na crítica literária que, normalmente, colocava em lados opostos os partidários da forma e os partidários do conteúdo, ou seja, as esferas da artee a da sociedade. Os conteúdistas, para quem se reserva a pecha de serem antes sociólogos que críticos culturais, costumam olhar a arte como reflexo de uma realidade cujos esquemas históricos ou políticos são previamente conhecidos. Desse ângulo, a arte não traria nenhum conhecimento novo, apenas ilustraria, de modo mais ou menos fidedigno, o que já sabíamos sobre o curso do mundo. O outro lado, o que venceu o debate, reconhece que a forma é o elemento crucial da arte, o que a eleva acima da vida social, para uma esfera fora das injunções da história e sem referência ao mundo real. O preço dessa visão formalista é serrar as relações entre arte e sociedade. Ao invés de procurar ler a obra na sociedade e a sociedade na obra, os modos de ler preconizados pelas diferentes escolas críticas buscavam isolar o texto literário do contexto que lhe dá sentido: assim foi com o formalismo russo com sua ênfase nas técnicas de composição nos anos 1920, e com o "close reading", com sua atenção restrita às palavras sobre a página. Esta leitura puramente intrínseca da literatura, partindo da Inglaterra nos anos 1930 e dominando a academia norte-americana sob o nome de New Criticism a partir dos anos 1950, tornou-se, como sabemos, a maneira "natural" de ler um texto. A moda seguinte de ler, o estruturalismo, mantém essa atenção na obra isolada da sociedade, e se concentra na evolução sistêmica da literatura como uma atividade autônoma e nas interações complexas entre estratégias e procedimentos formais. Esta ênfase no texto autotélico permanece em tendências contemporâneas como o desconstrutivismo com sua concepção textual da realidade: para Derrida, principal nome dessa tendência, "não há nada exterior a um texto" e o trabalho crítico passa por desmontar as oposições binárias que constituem a linguagem e buscar a "différance", o que não se encaixa, o excesso linguístico. Essa predominância formalista se, por um lado, significou um 
$|18|$

O diferencial da crítica materialista

ganho com suas análises detalhadas de procedimentos técnicos e de seus efeitos, fez com que se criasse uma "mentalidade disjuntiva" para falar como Antonio Candido: ou se estudava o texto como todo autônomo cuja estrutura formal era o único objeto digno de atenção, ou se estudava a literatura como fato da cultura. Uma das consequências dessa mentalidade disjuntiva é transformar a literatura em adorno do espírito.

A intervenção da tradição materialista vem alterar radicalmente os termos do debate. Com os formalistas, considera que a forma é central na arte, mas está longe de subestimá-la como mero ornamento ou acidente de percurso criativo. Para usar uma formulação de Adorno, forma para esta tradição é conteúdo sócio-histórico sedimentado. Essa ideia complexa e enriquecedora de forma começou a se firmar em diferentes tradições críticas nacionais a partir dos anos 1940 e tem sua primeira codificação no Brasil na obra de Antonio Candido. Falando do mestre, e com observações que se aplicam à toda a tradição, Roberto Schwarz esclarece as possibilidades abertas por essa ideia de forma:

[...] os constrangimentos materiais da reprodução da sociedade são eles mesmos formas de base, as quais mal ou bem se imprimem nas diferentes áreas da vida espiritual, onde circulam e são reelaboradas em versões mais ou menos sublimadas ou falseadas, formas, portanto, trabalhando formas. [...] Do ângulo dos estudos literários, o forte dessa noção está no complexo heterogêneo de relações histórico-sociais que a forma sempre articula, e que faz da historicidade, a ser decifrada pela crítica, a substância mesma das obras. A vantagem ressalta no confronto com os diferentes formalismos - termo confuso que pensa designar pejorativamente a superestimação teórica do papel da forma, quando talvez se trate, pelo contrário, de uma subestimação. Com efeito, os formalistas costumam confinar a forma, enxergar nela um traço distintivo e privativo, privilégio da arte, aquilo que no campo extra-artístico não existe, razão por que a celebram 
como uma estrutura sem referência. (SCHWARZ, 1999, p. 30 e 31, destaque do autor).

Essa concepção de uma forma objetiva embasa uma prática distinta e abre um enorme horizonte de relevância para a crítica cultural. Invés de avaliar obras de arte e arbitrar qual vai para o cânone ou qual fica relegada ao esquecimento, a prática desse tipo de análise não pára na descrição, mas busca decifrar os liames entre as formas da arte e a história que elas concretizam. Nesse movimento, a tradição evidencia em que sentido as escolas formalistas subestimam a forma e com ela a tarefa da crítica literária, condenada, na tradição hegemônica, a repetir fórmulas ou generalidades, sem objeto efetivo. Todos nos lembramos das conclusões decepcionantes das intrincadas descrições formais do New Criticism que nos diziam, depois de interessantes observações sobre as palavras na página, que o central no poema era demonstrar a "a ambigüidade da linguagem", ou a complexidade do significado, ou ainda, como querem os desconstrutivistas, que a linguagem nunca diz tudo. Demasiado e admirável esforço, pena que seja para arrombar uma porta aberta e nos contar, exatamente como fazem os conteudistas, algo que já sabíamos muito antes de ler a obra.

A retirada estratégica da crítica afirmativa para o campo da reiteração de generalidades humanistas, deixou o campo da relevância social aberto para a atuação da crítica materialista. De seu ponto de vista declaradamente empenhado, o básico está justamente nas relações entre formas culturais e formas sociais.

Dada essa situação, não é de admirar que a crítica cultural marxista tenha formulado as balizas que pautam o pensamento crítico produtivo sobre a vida cultural de nossos dias. Há muitas correntes dentro do marxismo, mas a maior contribuição para a crítica cultural vem de uma tradição que um dos seus grandes pensadores, Perry Anderson, apresenta como a do Marxismo Ocidental, para distingui-la da produção marcada pelas injunções dos partidos comunistas do leste. A obra conjunta desses pensadores, e a dos que levam adiante seus seguidores em nossos 
dias, realiza um eficiente trabalho de diagnóstico e demonstração do custo humano de se viver sob um modo de produção baseado na exploração e na primazia do lucro sobre a vida. $O$ fato de que essa demonstração seja feita a partir da análise dos significados, valores e modos de simbolização, em uma palavra, da cultura, que molda e dá sentido à experiência do vivido, lhe confere uma eficácia e um impacto que podem ser instrumentos importantes para manter aberto um espaço de dissidência no coro dos satisfeitos com o mundo vigente e assim tentar impedir que essa versão empobrecida da vida continue empilhando vitórias e acabe por colonizar o próprio futuro.

O primeiro grande livro da tradição do marxismo ocidental é de 1923, o História e Consciência de Classe do filósofo húngaro Georg Lukács ([1923] 1974). A partir da descrição poderosa do funcionamento do sistema em O Capital, Luckács mostra como as forças do modo de produção operam sobre os sujeitos, estruturando nossas próprias consciências e deformando nossos sentidos. Sua noção chave, a da reificação, mostra como a forma mercadoria, com seu poder avassalador de operar uma equivalência geral no sistema de trocas, mercantiliza todas as relações humanas escondendo, sob a fantasmagoria do fetiche, as pessoas que a produzem e consomem. Nesse processo, os sujeitos se transformam em objeto. Lukács acrescenta a este quadro a descrição de Max Weber do processo de racionalização dos processos produtivos, que conhecemos como taylorização, e mostra como esse processo se estende até nossas configurações mentais. Assim o sistema deforma tanto a esfera da produção material quanto a da produção do conhecimento e das artes. O fundamental no livro é a exposição convincente do caráter sistêmico da lógica do capitalismo, um processo que separa, compartimentaliza, especializa e dispersa, uma força que opera sobre todas as coisas e que tem que ser entendida e combatida em suas mais diferentes manifestações.

É claro que a cultura é marcada por esse processo de reificação que ela a um só tempo incorpora, reforça e, para alguns, supera. Com História e Consciência de Classe está aberto o caminho para que a crítica da cultura vá muito além de seu serviço usual 
de apresentar um comentário e uma avaliação das tais grandes obras da humanidade. Na era em que os meios de comunicação de massas começam a se expandir, base material para o que depois se veio a chamar a Era da Cultura, a teoria marxista se acha equipada para se constituir em uma fenomenologia da vida cotidiana sob o capitalismo tornando-se, assim, um dos mais poderosos instrumentos de descrição e de aferição da realidade sócio-histórica.

Isso se vê claramente no próximo grande avanço, o trabalho da Escola de Frankfurt. Sua ambição é máxima: no mundo reduzido e fragmentado do fetiche é preciso construir uma teoria social sistemática e abrangente, que possa enfrentar as principais questões de seu momento histórico. O central na produção diversificada dos frankfurtianos é preservar a capacidade reflexiva tanto dos ditames totalitários do então mundo comunista quanto das ilusões do individualismo mercantilizado do capitalismo administrado.

O resultado é a produção de um discurso crítico que se tornou canônico para se entender a cultura contemporânea mesmo entre os que não compartilham das posições políticas desses pensadores. Em Dialética do Esclarecimento, de 1947, Adorno e Horkheimer ([1947]1985) introduzemanoçãodeindústriacultural, demonstrando a relação sempre escamoteada, entre produção simbólica e produção material. A nova cultura dita de massas tem como alvo administrar o lazer da população, treinando-a para ouvir sempre a voz do dono, que demanda a formação de consumidores passivos. Também de Adorno é a demonstração do embotamento dos sentidos levado a efeito pelo dito progresso do capitalismo, exemplificado na regressão da nossa audição que nos incapacita de efetivamente ouvir música ou de pensar para além dos ditames do fetiche. Este é apenas um entre os índices do empobrecimento real da experiência em um sistema que se apresenta como o provedor da abundância. $\mathrm{O}$ marxismo nos ensina que a única ideologia positiva que o capitalismo nos pode oferecer é a do progresso. Os frankfurtianos demonstram, através da análise da vida sob este sistema, a interpenetração entre progresso e retrocesso, entre o que 
se chama de civilização e o que se oculta sob a rubrica de barbárie. É este um dos sentidos do famoso aforismo de Walter Benjamin nas "Teses sobre a Filosofia da História": "Não há nenhum documento de civilização que não seja ao mesmo tempo um documento de barbárie".

Como se não bastasse tudo isso, a Escola de Frankfurt opera ainda a junção teórica do marxismo e da psicanálise freudiana, potencializando o alcance e significado da crítica cultural. Um dos exemplos está na constatação de Adorno de que a forma das obras de arte, com seus acertos e também com suas falhas, apresenta a historiografia inconsciente de seu tempo histórico. Trata-se de uma noção que amplia de modo considerável a capacidade de diagnóstico das análises, em especial em um tempo caracterizado pelo apagamento sistemático do passado. Essa idéia da História cifrada na forma estética será retomada pelo crítico norteamericano Fredric Jameson no seu livro de 1986, O Inconsciente político: a Narrativa como um Ato Social Simbólico onde é utilizada como um dos instrumentos de análise da narrativa, uma das formas fundamentais de dar sentido à experiência.

O encontro entre Marx e Freud marca também a obra de Herbert Marcuse para quem é necessário delinear uma construção teórica da cultura para além do princípio do desempenho, ou seja, para além do princípio que rege a sociedade capitalista. Na sua avaliação, na sociedade afluente do capitalismo pós-industrial vivemos um momento de neutralização universal. Em Eros e Civilização, cuja primeira edição é de 1955, ele dá exemplos de como essa neutralização pode ser verificada em vários âmbitos: no psíquico temos, com o esfacelamento da família nuclear, a atenuação do complexo de Édipo, e também o fechamento de uma possibilidade de formação da individualidade psíquica. No social, há uma atenuação da carga repressiva e da sublimação forçada de um período anterior, substituídas agora pelo que ele chama de "dessublimação repressiva". A sociedade da abundância encontra, entre outras formas de consumo, a sexualidade: como com as mercadorias, há que consumir sexo em abundância, mas de forma especializada, como uma compensação libidinal pelo 
empobrecimento da vida social. No âmbito político, a atenuação das formas clássicas de luta de classes é o chão objetivo desse processo de neutralização. Mesmo as novas formas de protesto e revolta não são mais objetos de censura direta ou de repressão, trocadas agora pela violência suave da cooptação. Que isso pareça uma descrição fiel do caldo cultural do século XXI é mais um atestado da permanência do sistema e da atualidade da crítica acurada que o marxismo ocidental lhe dirige.

Do ponto de vista teórico, o legado decisivo desses pensadores para o futuro pode estar na sua demonstração da necessidade histórica de se liberar o pensamento das amarras com que o aprisionam os impulsos de fragmentação e dispersão do capitalismo. Estes insistem em considerar em separado esferas que se interpenetram como as do sociológico e do psicológico, do trabalho e do lazer, do público e do privado, do material e do espiritual, do político e do cultural. Esse movimento, básico para uma crítica que por definição olha o mundo do ponto de vista da totalidade, marca o desenvolvimento do marxismo ocidental em suas diferentes manifestações.

Na França, a obra de Guy Debord traça um ponto importante dechegada do processo de abstração impulsionado pelo predomínio da forma mercadoria. Ele mostra que a imagem é a culminação do processo de reificação característico do sistema capitalista. Não é por acaso que seu grande livro de 1967, A sociedade do espetáculo, ecoa as linhas de abertura de O Capital. Em 1867, o fundamental era explicitar o funcionamento real do capital começando pelo exame de sua mínima forma constitutiva: "A riqueza das sociedades em que prevalece o modo de produção capitalista se apresenta como uma imensa acumulação de mercadorias". Com a indústria cultural impulsionando a todo vapor o funcionamento do sistema, Debord expõe as peculiaridades da nova fase do capitalismo: “Em sociedades em que prevalecem as condições modernas de produção, a totalidade da vida se apresenta como uma imensa acumulação de espetáculos". Retomando Luckás, ele ancora sua análise do funcionamento da sociedade do espetáculo nos processos materiais de separação e nas inversões que ele acarreta. O primeiro 
capítulo de seu livro, "A Separação Aperfeiçoada", demonstra como os anos 1960 apresentam o ponto de chegada desse processo cuja velocidade e abrangência só aumentaram em nossos dias. Longe de serem meros desenvolvimentos técnicos, os meios de comunicação de massa expressam o funcionamento do sistema em nossos dias. A palavra "comunicação" para descrever estes meios é enganosa: o espetáculo monopoliza a fala e apassiva os consumidores de imagens. A própria mensagem é a repetição contínua da apologia do sistema e da necessidade de sua continuação. A predominância do espetáculo dá notícia da colonização abrangente do mundo da vida pela forma mercadoria. Nesse sentido, o espetáculo é a forma final do fetiche. Funciona como eficiente mecanismo de ocultação das relações reais de produção. Sob sua égide, completa-se o processo de inversões que estrutura a forma mercadoria: os sujeitos passam a ser objetos passivos do bombardeamento de imagens escolhidas por outros; o abstrato, se apresenta como imagem tangível, ou até mesmo como a única forma do tangível, que se coloca para a contemplação do homem alienado. O próprio tempo se congela no presente eterno do espaço. A onipresença e o poder avassalador da imagem na sociedade de consumo evidenciam a predominância da esfera da cultura sobre todas as outras esferas da vida social. No mundo pós-moderno, como vai mais adiante teorizar Fredric Jameson, da economia às oscilações do desejo, tudo é mediado por imagem. O preço, para falar como Debord, é que "o espetáculo é a inversão da vida, o movimento autônomo do inanimado." É como se, adaptando as palavras de Marx, as imagens começassem a desenvolver ideias próprias e a "dançar por sua própria vontade."

Do outro lado do canal da Mancha também se estrutura uma resposta marxista às injunções da nova Era da Cultura. Como Debord, Raymond Williams (1979, 2011a, 2011b, entre outros) procura apresentar um diagnóstico e uma teoria da nova situação social. Ele enfatiza as interconexões entre processos históricos, sociais e artísticos e como eles se inscrevem na obras de arte e no próprio modo de vida. Seu objetivo central é construir uma forma de pensar a cultura que possibilite intervir nas mudanças 
qualitativas da vida social e transformá-la, de mera apologia ao sistema, em uma forma de luta que apresse o que ele chama de "a longa revolução", ou seja, uma interação entre uma revolução econômica, uma política e uma cultural. Seu projeto intelectual é justamente fazer a reavaliação das formas vigentes de pensar e analisar os significados e valores que constituem nosso modo de vida no sentido de abrir um espaço por onde possa se estruturar uma mudança social efetiva. Seu primeiro movimento é desmontar a dicotomia que o pensamento hegemônico instaura entre cultura e sociedade. Coerente com a tradição em que trabalha, Williams ([1958] 2011b) mostra o desenvolvimento histórico da separação entre produção social e produção cultural como uma forma de reação às mudanças radicais trazidas pela revolução industrial: era preciso instaurar um domínio da vida não marcado pela lógica desumana que faz com que tudo que parecia sólido se desmanchasse no ar: a cultura se presta a ocupar essa posição de refúgio dos valores humanos em uma situação social que os nega. Uma das consequências é que esta cultura apartada do mundo material se furta de efetivamente intervir neste mundo, colocandose sempre acima do existente em uma posição idealizada e abstrata que acaba ratificando o status quo e se esquivando de um efetivo engajamento com a construção social de significados e valores. Para Williams, é preciso recuperar a cultura como criação de uma sociedade, como materialização do seu modo de vida. Isso não apenas para desmistificar a criação cultural e desmontar os pressupostos da crítica idealista, mas para poder compreender esse modo de vida que se dá a ver em toda sua complexidade na produção cultural e tentar, a partir desse conhecimento, abrir um espaço para uma maneira de viver mais humana.

A extensa produção de Williams - mais de 20 livros cobrindo assuntos que vão da teoria da cultura à crítica da televisão e propostas concretas para uma modo de produção cultural mais democrático, marca a prática da crítica anglo-americana e, a partir daí de diferentes países do mundo de tal forma que se cria uma nova disciplina, os estudos culturais. O objetivo dessa disciplina é mudar o que se estuda, como e para que se estuda na área da 
cultura. Os estudos culturais expandem os estudos literários para incluir todas as outras manifestações culturais. Usam como forma de abordá-las uma noção marxista que pressupõe a inter-relação base material e produção cultural. O objetivo é entender o funcionamento da sociedade para modificá-lo. Com muitas mudanças e atenuações, os estudos culturais se firmaram em vários países como forma política de fazer crítica cultural.

Com essa herança poderosa não é de se espantar que a crítica cultural marxista venha acumulando sucessivas vitórias nas disputas interpretativas que marcam nossos dias. Em plena hegemonia do neo-liberalismo, Fredric Jameson (1996), o primeiro crítico cultural marxista da era da globalização, desmontou as ilusões dos discursos vigentes sobre o desmanche do sistema simbólico do modernismo, explicando, de forma muito mais convincente do que qualquer um dos outros discursos críticos na praça, que o pós-modernismo, mais do que um estilo, é a demonstração de que a lógica que azeita o funcionamento do capitalismo tardio é cultural. Mais do que nunca, o sistema que agora reina supremo, quase sem inimigos externos, necessita de uma sociedade saturada de imagens para dar a ilusão de resolver as contradições que o definem. Como antes, esse processo pode ser especificado pela análise de suas características inscritas na concretude da produção cultural. Jameson (1996) examina essas características a partir das concepções das categorias fundamentais que organizam o pensamento. O tempo se detém no presente eterno da mercadoria, perde-se o sentido da historicidade e o passado passa a ser retratado como apenas mais um estilo, como fazem os filmes de época; o espaço elimina a noção de distância e a substitui pela de superficialidades saturadas. O efeito primeiro dessas mudanças é impedir que o sujeito se localize no fluxo constante da mutações do mundo globalizado. Não é de se surpreender que a subjetividade contemporânea à deriva seja marcada pelo esmaecimento dos afetos e a alienação e angústia do sujeito moderno sejam substituídas pela fragmentação e pela indiferença. Nessa situação, torna-se cada vez mais necessária uma crítica que se coloque a contrapelo do movimento hegemônico. Não é por 
acaso que Jameson insiste sempre que é preciso relacionar cada elemento da nossa cultura com a História e com a totalidade das relações sistêmicas.

A produtividade dessemododepensar podeser demonstrada na amplitude e relevância da própria obra de Jameson, marcada por três extensíssimas linhas de atuação. Na boa tradição da dialética, que já foi definida como um pensar a respeito do próprio pensar, umas dessas linhas é a da invenção de categorias que nos ajudam a refletir sobre o presente. É o caso, por exemplo, do mapeamento cognitivo, uma das formas que a consciência de classe assume em tempos em que escasseiam os grandes movimentos de massa e a complexidade das relações globais aumentam a dificuldade de se estabelecerem as conexões entre os acontecimentos e as estruturas sistêmicas. O mapeamento cognitivo é uma forma da crítica que vai justamente buscar essas conexões na produção cultural. Outra forma que a invenção categorial assume na obra de Jameson é a de colocar de novo em circulação antigos termos, como, por exemplo, a noção de Utopia, que ele defende como uma bandeira necessária em um momento histórico em que não se deixam ver alternativas sistêmicas ao capitalismo. Assim, muitas de suas análises buscam demonstrar a contradição entre impulsos de reificação e de utopia em obras contemporâneas, indo desde o cinema degradado de Hollywood ou as formas da ficção científica, até as grandes obras dos modernistas consagrados. Uma segunda linha de atuação é da avaliação da conjuntura, da explicação dos períodos históricos. Já comentei aqui sua avaliação avassaladora do pós-modernismo, mas vale ainda lembrar seu ensaio de 1984, "Periodizing the 60s", em que demonstra como os avanços da assim chamada década revolucionária se restringiram à superestrutura e que a conta seria logo cobrada, como de fato o foi nos anos 1980 e 1990, pelas conhecidas exigências da infraestrutura. A mesma acuidade histórica aparece em sua análise de 1997 da cultura e do capital financeiro: ele termina com a previsão de que tanta as imagens estereotipadas da arte contemporânea quanto o fluxo dos capitais financeiros "estão se movendo, sem perceber, em direção a um crash" e isso anos antes da grande crise de 2008. A esses dois 
campos de atuação mais marcados, acrescente-se um grande trabalho e análise e interpretação de uma enorme variedade de obras: não conheço nenhum outro crítico que apresente uma gama tão distinta de interesses que abrangem diferentes formas de arte - Jameson fala de arquitetura, filosofia, literatura, cinema, teoria, artes plásticas - e diferentes culturas, demonstrando o enorme campo que as relações intensificadas pela globalização e pela acessibilidade da informação abrem para um intelectual empenhado. Como ele diz no seu livro publicado em 2009, Valences of the Dialectics, uma das tarefas do crítico dialético hoje é fazer com que a história apareça e seja reconhecida por todos.

O capítulo brasileiro da crítica cultural marxista compartilha dessa capacidade de decifração do movimento real da História como escrito nas produções culturais. O exemplo mais bem acabado dessa tradição no Brasil é a obra de Roberto Schwarz. Ele desmonta a recepção beletrista da obra de Machado de Assis e esclarece que ele é mesmo um dos grandes da literatura ocidental, mas não pelas razões que quer essa crítica, seja quando elogia seu uso da linguagem ou sua familiaridade com os clássicos. Roberto Schwarz (1990) mostra que Machado é efetivamente um mestre da forma literária, capaz de cifrar em sua obra a particularidade do funcionamento local das concepções ditas universais que embasam o conjunto de idéias que regem a modernidade. Submetidas ao crivo da experiência periférica, essas ideias giram em falso e nos permitem enxergar seus efetivos pressupostos tanto lá como cá. Este um dos fundamentos do significado histórico mundial do nosso primeiro grande escritor. Um dos interesses maiores da obra crítica de Roberto Schwarz é que ele mostra como as condições históricas do movimento peculiar da vida social na periferia moldam uma subjetividade específica que é exposta pela arte de Machado de Assis. A volubilidade monstruosa dos heróis dos romances maduros, firmemente assentada nos privilégios de classe garantidos pelo regime, é uma ilustração clara do tipo de ser humano que tal regime engendra. Eles representam o avesso revelador do sujeito burguês, que no centro aparece disfarçado sob camadas de ideologia humanista. Também nesse sentido, 
a obra crítica de Roberto Schwarz adquire uma relevância muito mais ampla do que a que chama a atenção dos estudiosos da vida brasileira. Como sua obra demonstra, a periferia é o lugar em que a verdade do centro e, portanto, do funcionamento social do sistema que cria centros e periferias, está em grau máximo de visibilidade entre nós. Ficam evidentes em seus estudos sobre Machado as raízes históricas dos aspectos mais intoleráveis da vida social sob o capitalismo.

Estas são algumas das características que constituem o diferencial de uma crítica materialista.

\section{Referências}

ADORNO, Theodor e HORKHEIMER, Max. Dialética do esclarecimento: fragmentos filosóficos. Trad. Guido A. Almeida Rio de Janeiro: Zahar, 1985.

BENJAMIN, Walter.“Teses sobre filosofia da história” In: KOTHE, Flávio R. (Org.) Walter Benjamin: sociologia. São Paulo: Ática, 1985. p. 153-164.

DEBORD, Guy. A sociedade do espetáculo. Rio de Janeiro, Contraponto, 1997.

JAMESON, Fredric. Valences of the Dialectic. London and New York: Verso, 2009.

Pós-modernismo, a lógica cultural do capitalismo tardio. Trad. Maria Elisa Cevasco. São Paulo: Ática, 1996.

O inconsciente político: a narrativa como ato socialmente simbólico. Trad. Valter L. Siqueira. São Paulo: Ática, 1992.

"Periodizing the 60s," Social Text, n. 9/10, Spring-Summer, 1984. LUKÁCS, Georg. História e consciência de classe. Porto: Escorpião, 1974. 
MARCUSE, Herbert. Eros e Civilização - uma interpretação filosófica do pensamento de Freud. Trad. Álvaro Cabral. Rio de Janeiro: Zahar, 1975.

SCHWARZ, Roberto. "Um crítico na periferia do capitalismo". Entrevista concedida a Luiz Henrique Lopes dos Santos e Mariluce Moura. Revista Pesquisa Fapesp, 103, setembro de 2004.

"Adequação nacional e originalidade crítica". In: Sequências Brasileiras. São Paulo, Companhia das Letras, 1999.

. Um mestre na periferia do capitalismo: Machado de Assis. São Paulo: Duas Cidades, 1990.

WILLIAMS, Raymond. Cultura e materialismo. Trad. André Glaser. São Paulo: Editora Unesp, 2011a.

Cultura e sociedade: de Coleridge a Orwell. Trad. Vera Joscelyne. Petrópolis: Editora Vozes, 2011b.

. Marxismo e literatura. Trad. Waltensir Dutra. Rio de Janeiro: Zahar, 1979. 